\title{
LA SINDÉRESIS O RAZÓN NATURAL COMO LA APERTURA COGNOSCITIVA DE LA PERSONA HUMANA A SU PROPIA NATURALEZA UNA PROPUESTA DESDE TOMÁS DE AQUINO
}

\author{
Juan Fernando Sellés \\ Universidad de Navarra
}

\begin{abstract}
RESUMEN
La sindéresis, también llamada por Tomás de Aquino razón natural, es cognoscititiva: un hábito innato por medio del cual la persona humana conoce y regula su naturaleza humana, y en especial, su razón (tanto teórica como práctica) y su voluntad, y está abierta a éstas facultades, tanto en su estado nativo como activadas. La sindéresis se conoce por medio de otro hábito innato, la sabiduría, y ambos dependen del intelecto agente.
\end{abstract}

Palabras clave: Tomás de Aquino, sindéresis, razón natural, sabiduría.

\begin{abstract}
The synderesis, also named by Saint Thomas natural reasoning (natural mind) is cognoscitive: a innate habit through whom the human person knows and regulates its human nature, and specially its reason (either theoretical and practical), and it is open to these faculties, in its native state and in the activation. The synderesis is known by means of the habit of Wisdom, and both of them depend of the intellectus agens.
\end{abstract}

Key words: Thomas of Aquino, Synderesis, Natural mind, Wisdom.

\section{INTRODUCCIÓN}

La psicología en sentido clásico, que no según la deriva experimental sufrida a la largo del s. XX, se consideraba como el estudio del alma y de sus facultades. El alma humana no es asunto fácil de conocer. Algùnos piensan incluso que no se puede conocer. Los medievales no sostuvieron una tesis tan radical, pero baste pensar en la diversidad de pareceres al respecto entre dos grandes pensadores del periodo de esplendor de la escolástica: Tomás de Aquino y Escoto. Para el primero el alma es el principio de la vida del que nacen todas las facultades. Para el segundo, en cambio, lo que llamamos alma, se reduce a las dos facultades superiores: inteligencia y voluntad.

Tampoco las facultades humanas son asunto fácil de conocer, precisamente porque son facultades, es decir, potencias, y es sabido que lo potencial, por definición, es lo velado. Los actos de las facultades son lo claro de conocer. De ahí que Tomás de Aquino advierta que las facultades se conocen por sus actos ${ }^{1}$. En efecto, los actos de las facultades no sólo se pueden co-

1 En el conocer, las potencias se conocen por los actos, y éstos por los objetos. Cfr. In I Sententiarum, d. 3, 
nocer, sino que incluso en orden a ellos se puede formular una teoría axiomática del conocimiento humano ${ }^{2}$, y en atención a los actos de la voluntad, también se puede proponer en parte una teoría axiomática de la voluntad ${ }^{3}$.

La siguiente cuestión, que se puede formular more kantiano, es la siguiente: ¿por qué la psicología todavía hoy no ha conseguido el estatuto de ciencia? Desde luego que hay muchísimo trabajo hecho. Pero también excesivas discrepancias de escuela, y dentro de cada una de ellas, constantes rectificaciones a sus precedentes postulados en la medida que avanza el tiempo y la investigación. Considero que la respuesta es la siguiente: porque todavía no conocemos con rigor (de ciencia) qué sea su objeto propio, «lo psíquico», y tampoco cuál sea el método de conocimiento que se debe emplear para conocer tal objeto, es decir, la instancia cognoscitiva humana proporcionada para conocer ese campo temático. Es decir, no se conoce a ciencia cierta cuál es el objeto diferencial de la psicología (lo que tradicionalmente se llamaba alma, sus facultades en estado nativo, y el carácter distintivo de ellas), y a su vez, también se desconoce, y aun en mayor medida, el método cognoscitivo natural humano apropiado para conocer tal objeto.

No conocemos con rigor al alma y a sus facultades, el tema, lo psíquico, seguramente porque desconocemos cuál es la instancia, el método, que permite tal conocimiento. La búsqueda de respuesta apunta, a mi modo de ver, a la sindéresis como a esa instancia cognoscitiva humana que arroja luz sobre lo que llamamos alma y facultades humanas. De ahí el interés por este estudio.

\section{UNA CUESTIÓN DE MÉTODO: ¿CÓMO CONOCER LA SINDÉRESIS?}

De ordinario se ha atendido poco a la sindéresis y con no demasiada profundidad. En efecto, la mayoría de los pensadores desconocen que tengamos tal instancia cognoscitiva. Y de entre los pocos que reparan en ella, unos la hacen coincidir con un acto cognoscitivo, otros con la conciencia moral; otros como el hábito de los primeros principios prácticos (sin destacar, además, con suficiencia, qué y cuáles sean tales principios). Parece, pues, un ámbito temático borroso, y paradójicamente se puede tomar así, porque la sindéresis no es un ámbito temático sino, ante todo, un método cognoscitivo; no es en primera instancia lo conocido, sino el conocer. Desde luego que se puede conocer el conocer, pero no como un objeto conocido. En todo caso, la sindéresis será tema para un método cognoscitivo superior a ella, pero no para ella misma, porque en el conocimiento humano nada es autoreferente ${ }^{4}$.

La sindéresis es una realidad humana, y si es superior a la razón y voluntad, será más humana que aquéllas. Pero lo más intrínsecamente humano es lo claro, porque es acto. Por eso,

q. 1, a. 2 ad 3; d. 17, q. 1, a. 4, co y ad 4; d. 17, q. 1, a. 5, ad 4; In II Sententiarum, d. 23, q. 2, a. 1,co; d. 44, q. 2 , a. 1, co; In IlI Sententiarum, d. 9, q. 2, a. 1, sc. 2; d. 9, q. 2, a. 2, co; q. 14, q. 1, a.. 2, b, ad 2; d. 23, q. 3, a. 1, c, sc. 1 ; d. 24 , q. 1, a. 1 , a, ad 5; d. 33, q. 1, a. 1, c, sc, 2 ; d. 33, q. 2, a. 1, a, co; d. 34 , q. 1, a. 6, co; d. 34 , q. 2 , a. 3 , a, sc. 2 ; d. 34 , q. 2, a. 3 , b, sc. 2 ; In IV Sententiarum, d. 14, q. 1, a. 1, c, sc. 1 ; d. 15 , q. 2, a. 1, a, ad 2; d. 16, q. 3, a. 2, b, ad 2; d. 41, q. 1 , a. 4 , a, sc. 1 ; d. 49 , q. 2 , a. 5 , co; d. 50 , q. 1, a. 3, co; $Q . D$. De Veritate, q. 10, a. 9, ad 7; q. 15, a. 2, co; q. 19, a. 1, sc. $2 ; Q$. D. De Anima, q. 13.sc1; q. 16, ad 8; In De Anima, lib. I. lec. 7, n. 16; lec. 8, n. 5; In De Anima, lib. 2, lec. 2, n. 1; Super ad Hebraeos, 11, 1/21; In Dionysii de Divinis Nominibus, 4, 1/61; In Ethicorum, 1. 4, cap. 6, n. 7; 1. 5, cap. 16, n. 13; 1. 6, cap. 3, n. 10; Summa Contra Gentes, 1. 1, n1; De Substantiis Separatis, 20/344; Summa Theologiae, I ps., q. 77, a. 3, sc; q. 78, a. 1, co; I-II ps., q. 17, a. 3, ad 2; q. 54, a. 2, sc; II-II ps., q. 4, a. 1, co; q. 81, a. 3, co. En la voluntad también los actos se conocen por los objetos, cfr.In IV Sententiarum, d. 15, q. 3, a. 1,c, co; Q. D. De Potentia, q. 2, a. 3, ad 3; Summa Contra Gentes, 1. 3, cap. 26, n. 9.

2 Cfr. Polo, L., Curso de Teoría del Conocimiento, vols. I-V, Pamplona, Eunsa, 1985-96.

3 Cfr. mi artículo: «La extensión de la axiomática según Leonardo Polo», en Studia Poliana, 2 (2000), pp. $72-113$.

4 Cfr. mi libro Conocer y amar. Estudio de los objetos y de las operaciones del entendimiento y de la voluntad según Tomás de Aquino, Pamplona, Eunsa, $2^{\mathrm{a}}$ ed., 2000. 
los avances en la axiomatización de la antropología trascendental en los últimos años son indudables $^{5}$. Asimismo, como se ha adelantado, los de la teoría del conocimiento y de teoría de la voluntad. También los de metafísica ${ }^{6}$. Y se puede intentar la aximatización de la ética ${ }^{7}$. Por su parte, aunque la física clásicamente considerada, no se puede axiomatizar, debido precisamente a la potencialidad de lo físico, se han detectado sus principios o causas ${ }^{8}$ con suficiencia desde Aristóteles. Además, eso que es la antropología trascendental (que estudia el acto de ser, núcleo, o intimidad de la persona humana) respecto de la inteligencia y voluntad, (que forman parte de la esencia humana) eso, (salvando las distancias, porque no se da una simetría), es lo que es la metafísica respecto de la física. Pero entre las teoría del conocimiento y de la voluntad y la antropología trascendental está la psicología. Sin embargo, se pasa de unas a la otra sin tener suficientemente en cuenta a ésta. En suma, ni la psicología es ciencia, ni se sabe a ciencia cierta qué sea la sindéresis, y ambas ignorancias van aunadas.

Con palabras tomistas: hay una distinción neta entre persona humana y naturaleza humana ${ }^{9}$. Esa distinción es fruto de ver la composición real de todo lo creado, advertida por Tomás de Aquino, entre actus essendi y essentia en el hombre. La persona, cada quién, es el acto de ser. El cuerpo y todas las funciones y facultades, tanto sensibles como inmateriales, pertenecen a la esencia humana, a lo común del género humano, a eso que todos los hombres tenemos a nuestra disposición, y que cada uno encarna y personaliza de modo distinto. Pues bien, la tesis que aquí se pretende sostener, con apoyatura en textos tomistas, es que la sindéresis es el puente, o el enlace, entre la persona humana y su naturaleza. Esto es, mediante ella, la persona activa y conoce el estado de las potencias de su naturaleza, en especial, de su inteligencia y de su voluntad, porque son las más altas de la naturaleza, las más cercanas a la persona y las más susceptibles de ser desarrolladas por la persona.

\section{LA HISTORIA, LOS NOMBRES (SINDÉRESIS O RAZÓN NATURAL) Y LA ESENCIA}

Sorprende que la sindéresis no figure en el elenco de los hábitos cognoscitivos descubiertos por Aristóteles. Tampoco está presente en los escritos de los demás pensadores griegos y latinos antiguos. Al parecer el hallazgo se debe a San Jerónimo, quién la denominó «la chispa de la conciencia» ${ }^{10}$. Con todo, esta averiguación estuvo latente hasta los escolásticos, siendo con ellos con quienes propiamente nació su estudio ${ }^{11}$. Tomás de Aquino alude a la sindé-

5 Cfr. Polo, L., Antopología Trascendental (I), Pamplona, Eunsa, 1999; PIÁ, S., El hombre como ser dual. La antropología trascendental de Leonardo Polo, Pamplona, Eunsa, 2001.

6 Cfr. Polo, L., El ser I, Pamplona, Eunsa, 1997; «El conocimiento habitual de los primeros principios», en Nominalismo, idealismo y realismo, Pamplona, Eunsa, 1997.

7 Cfr. Polo, L., Ética: hacia una versión moderna de temas clásicos, Madrid, Aedos, $2^{\text {a }}$ ed., 1997.

8 Cfr. Polo, Curso de Teoría del Conocimiemto, V, Pamplona, Eunsa, 1996, El conocimiento racional de la realidad, Curso de Doctorado, Universidad de Navarra, 1992, pro manuscripto.

9 «Persona significa lo perfectísimo en toda la naturaleza», Suma Teológica, I ps., q. 29, a. 3, co. «Este nombre de persona no ha sido impuesto para significar el individuo por parte de la naturaleza, sino para significar la realidad subsistente en tal naturaleza», Ibidem, I ps., q. 30, a. 4, co. «La persona significa un ser subsistente distinto en la naturaleza intelectual», De Potentia, q. 2, a. 4, co.

10 «scintilla conscienciae in Cain quoque pectore, postquam eiectus est de Paradiso, non extinguitur, et qua victi voluptatibus, vel furore, ipsaque interdum rationis decepti similitudine, nos peccare sentimus», Glossa ordin. Ezechiel, I, c. 1 (PL 25, 22 A-B).

11 Cfr. Crowe, M.B., «The term synderesis and the scholastics», en Irish Theological Quarterly, 1956, pp. 151-164; SciuTo, I., «Sinderesi, desiderio naturale e fondameto dell'agire morale nel pensiero medievale. Da San Tommaso s Meister Eckhart», en L'etica e il suo altro, Milano, Franco-Angeli, 1994, pp. 126-149. 
resis en contadísimos pasajes del sus escritos ${ }^{12}$. Sin embargo, en el corpus tomista, sindéresis equivale a razón natural: «la razón natural... se llama sindéresis» ${ }^{13}$. Y esta segunda denominación se emplea en otros muchos textos tomistas. No obstante, los estudiosos de este tema en los pasajes del de Aquino suelen ceñirse al vocablo sindéresis ${ }^{14}$. Por lo demás, huelga reiterar que, al margen de la vertiente de unos pocos comentadores tomistas de todos los tiempos ${ }^{15}$, ha sido éste un tema olvidado en la filosofía moderna y contemporánea.

Según Tomás de Aquino la razón natural es una para cada hombre ${ }^{16}$, y es cognoscitiva: «el hombre por la razón natural asiente según el intelecto a alguna verdad y doblemente se perfecciona respecto de ella, en primer lugar, sin duda, porque la alcanza; en segundo, porque tiene juicio cierto de ella» ${ }^{17}$. La razón natural, además, no se pierde, aunque puede disminuir su luz por culpa personal cuando uno actúa en contra de lo que establece la sindéresis ${ }^{18}$.

Su cometido es orientar la actuación humana de acuerdo con el modo de ser de la naturaleza del hombre ${ }^{19}$. Por tanto, la sindéresis debe estar abierta cognoscitivamente a todas las facultades humanas, pues de lo contrario no podría ser la regla de la actuación humana ${ }^{20}$. Su gobierno se vierte, como veremos, fundamentalmente sobre la inteligencia y la voluntad, pero como bajo éstas dos facultades espirituales subyacen todas las demás potencias corporales inferiores, se puede decir que la sindéresis gobierna toda la naturaleza humana ${ }^{21}$.

12 Cfr. In II Sententiarum, d. 7, q. 1, a. 2, ad 3; d. 24, q. 2, a. 3, co; d. 24, q. 3, a. 3, ad 4 y 5; d. 24, q. 2, a. 4, co; d. 39, q. 3, a. 1, co; In III Sententiarum, d. 33, q. 2, a. 4, d, co; Q.D. De Veritate, q. 16, a. 1, co; q. 16, a. 2, co; q. 16, a. 3; q. 17, a. 1 , co y ad 6; q. 17, a. 2, co; q. 18, a. 6, sc: q. 24, a. 5, sc; Q.D. De Malo, q. 3, a. 12, ad 13; q. 16, a. 6, sc. 5 y rc. 6; Summa Theologiae I ps., q. 79, a. 12, co; a. 13, co; I-II ps., q. 94, a. 1, ad 2; II-II ps., q. 47, a. 6, ad 1; Super ad Ephesios, cap. 4, 1c. 6/74-78.

13 Summa Theologiae, II-II ps., q. 47, a. 6, co y ad 1.

14 Cfr. GonzÁlez, A. M., De veritate 16 y 17, La sindéresis y la conciencia, Cuadernos de Anuario Filosófico, Seria Universitaria, Pamplona, Eunsa, 1999; Te VELDE, R.A., «Natural reason in the Summa contra Gentiles», en Medieval Philosophy and Theology, 4 (1994), pp. 42-70; LISSKA, A.L., Aquina's theory of natural law. An analytic reconstruction, Oxfort, Clarendon; New York, Oxfort University Press, 1996; Borgonovo, G., Sinderesi e coscienza nel pensiero di san Tommaso d'Aquino, Fribourg, Éditions Universitaires, 1996.

15 En cuanto a los comentadores tomistas, cfr. CAPREOLO, In l. III Sententiarum, d. XXXVI, q. I, ed. cit, vol. V, p. 431 b; Cayetano, In Summa Theologiae I-II q. 51, a 1, n 2; Sllvestre de Ferrara, In Summa Contra Gentes, c. 78, n I, 3; JuAn DE Sto. Tomás, Cursus Theologicus, In 1-2, q. 62, d. 16, a. 2; Cursus Philosophicus, Logica II, q. 26, a. 1; RamíREZ, S., «De habitibuus in commune, In I-II Summae Thelogiae Divi Thomae Expositio», qq. XIIX-LIV, en Opera Omnia, ed. cit., Madrid, CSIC, vol VI.

16 «atio naturalis unius est una tantum», Summa Contra Gentes, 1. II, cap. 24, n. 3.

17 Summa Theologiae, II-II ps., q. 9, a. 1, co.

18 «Ex hoc ipso quod aliquis peccat contra dictamen rationis naturalis, incurrit culpam», Q.D. De Malo, q. 4, a. 2, ad 22. En este punto se centra la réplica avant la lettre de TOMÁS DE AQUINO a OCKHAM: «non enim est peccatum solum quia est prohibitum, sed quia est contra rationem naturalem, ut etiam Philosophus dicit in I Politicorum», Quodlibet, n. 3, q. 7, a. 2, co. Con todo TOMÁs DE AQUNO declara que la razón natural puede morir, aunque tal vez sea sólo un modo de decir: «lex in homine dominatur, scilicet naturalis, quanto tempore vivit, scilicet lex in homine. Quae quidem vivit, quandiu ratio naturalis efficaciter in homine viget. Moritur autem lex naturalis in homine quandiu ratio naturalis passionibus succumbit. Is. 24,5: dissipaverunt fordus sempiternum, scilicet legis naturalis», Super ad romanos, cap. 7, Ic. 1/39.

19 «Finis praestituus homini secundum naturalem rationem, naturalis enim ratio dictat unicuique ut secundum rationem operetur», Summa Theologiae, II-II ps., q. 47, a. 7, co.

20 «Ad opera virtutum dirigimur per rationem naturalem, quae est quaedam regula operationis humanae», Summa Theologiae, I-II ps., q. 108, a. 2, ad 1.

21 \&Per operationes egredientes a ratione naturali et voluntate, in quibus praexistunt seminaria virtutum, acquiritur habitus in irascibili et concupiscibili; et per operationem voluntatis et rationis, inquantum sunt finis et principiorum primorum acquiritur in eis, quantum ad ea quae sunt ad finem, et quantum ad conclusiones, habitus scientiae et virtutis», In III Sententiarum, d. 33, q. 1, a. 2, b, ad 2. 


\section{LA SINDÉRESIS COMO HABITO INNATO}

Para Tomás de Aquino la sindéresis es, sin duda, un hábito: «synderesis est habitus» 22 . Y un hábito, como se ha indicado, cognoscitivo, pues lo propio de él es juzgar ${ }^{23}$. De modo que no es un acto, una operación inmanente de la razón. Pero tampoco es un potencia: «la sindéresis de distingue de las demás potencias, pero no como diversa por la sustancia de la potencia, sino por el hábito» ${ }^{24}$. Tampoco, claro está, es una virtud. La siguiente cuestión es saber de qué tipo de hábito se trata. La respuesta tomista tampoco deja lugar a dudas: es un hábito innato: «la sindéresis... es en cierto modo innato a nuestra mente» 25 .

Pero si es innato, no depende del hombre y de su adquisición, sino que es una dotación creatural natural ${ }^{26}$. De manera que no cabe más posibilidad que sea debido al «inventor», por así decir, del hombre: Dios. Efectivamente, «la razón natural... (procede o se debe) inmediatamente de Dios» ${ }^{27}$. A su vez, su modo de proceder, responde a la pauta divina impresa para tal hábito, es decir, que la razón natural es movida por Dios, que usa de ella como de instrumento ${ }^{28}$.

Ahora bien, hábito (de habere), indica posesión. Por tanto, la sindéresis es un modo de tener; es algo según lo cual la persona humana dispone, no algo que ella es. Es algo según lo que la persona tiene. Pero como es una posesión innata, la poseemos sin posibilidad de que se pierda $^{29}$. $Y$ en este sentido se puede decir que es un modo de poseer perfecto: la luz natural de la razón es una posesión perfecta para el hombre ${ }^{30}$. Lo que se tiene a través de ella, como se ha aludido, es la entera y propia naturaleza humana.

Si es un hábito cognoscitivo y es innato, será la fuente de todo conocer adquirido posterior, porque los hábitos adquiridos (que se fraguan en la inteligencia y voluntad) son la activación o perfeccionamiento de las facultades espirituales humanas por la sindéresis. En efecto, «en la naturaleza humana..., conviene que exista un conocimiento de la verdad sin inquisición..., y conviene que este conocimiento sea el principio de todo el conocimiento posterior... Por lo cual, conviene que este conocimiento sea inherente al hombre por naturaleza, ya que este conocimiento es, sin duda, como la semilla de todo otro conocimiento posterior... Y conviene que este conocimiento sea habitual, de modo que pueda ser usado fácilmente cuando sea necesario» ${ }^{31}$.

Hábito indica posesión, algo que se tiene, y por tanto, una perfección. Ahora bien, lo perfecto, por definición, no puede estar en estado potencial. Sin embargo, a pesar de eso, Tomás

22 In II Sententiarum, d. 24, q. 2, a. 3, sc. 1, 2 y co. «Sinderesis non est potentia, sed habitus... unde et principia operabilium nobis naturaliter indita, non pertinent ad specialem potentiam; sed ad specialem habitum naturalem, quem dicimus synderesim», Summa Theologiae, I ps., q. 79, a. 12, co.

23 Cfr. In II Sententiarum, d. 24, q. 2, a. 3, ad 2 y ad 4.

24 In II Sententiarum, d. 24, q. 2, a. 3, ad 1. Y antes ha escrito: «synderesin a ratione practica distinguitur non quidem per substantiam potentiae, sed per habitum», In II Sententiarum, d. 24, q. 2, a. 3, co.

25 In II Sententiarum, d. 24, q. 2, a. 3, co.

26 «Naturalis habitus datur in creatione», In III Sententiarum, d. 23, q. 3, a. 2, ad 1.

27 Summa Theologiae, I ps., q. 111, a. 1, ad 2. «signatum est super nos lumen vultus tui, domine quasi lumen rationis naturalis, quo discernimus quid sit bonum et malum, quod pertinet ad naturalem legem», Summa Theologiae, I-II ps., q. 91, a. 2, co.

28 «st tamen communiter de ratione naturalis et voluntarii motus, quod sint a principio intrinseco», Summa Theologiae, I-II ps., q. 6, a. 1, ad 3. El que la inclinación de la voluntad al fin sea también natural se debe a que tal movimiento es establecido por la sindéresis: «actus voluntatis nihil est aliud quam inclinatio quaedam procedens ab interiori principio cognoscente... (lo violento) est contra rationem naturalis inclinationis vel motus», Summa Theologiae, I-II ps., q. 6, a. 4, co.

29 «Habitus naturalis nunquam amittitur, sicut patet de habitu principiorum speculativorum, quem semper homo retinet; et simile est etiam de synderesi», In II Sententiarum, d. 24, q. 2, a. 3, ad 5.

30 Cfr. Summa Theologiae, I-II ps., q. 68, a. 2, co.

31 Q.D. De Veritate, q. 16, a. 1, co. 
de Aquino incluye nativamente la sindéresis dentro de la potencia de la razón: «este hábito no existe en otra potencia que en la razón ${ }^{32}$, asunto que no parece correcto, pues si el hábito es un conocimiento innato, no puede inherir en una potencia que es cognoscitivamente tabula rasa en su punto de partida. Ahora bien, si en la naturaleza humana no existe nada activo de entrada, salvo las funciones vegetativas que, obviamente, no son cognoscitivas, este hábito no puede pertenecer a la naturaleza humana, sino a lo nativamente activo, que no es otra cosa que la persona, o con palabras tomistas, «el hábito no puede ser principio de la persona subsistente sino que sigue al ser» ${ }^{33}$. La persona es el ser, el actus essendi en el hombre, y la sindéresis sigue a la persona. No es la persona, pero es un hábito nativo suyo.

\section{LA SINDÉRESIS ACTIVA E ILUMINA LA RAZÓN}

Acabamos de advertir que todo conocimiento discursivo o con inquisición debe proceder de un conocimiento natural activo, que sea directo, inmediato, experiencial. «Todo juicio de la razón humana - escribe Tomás de Aquino- se deriva igualmente de la razón natural» ${ }^{34}$. Pero la razón argumentativa o discursiva tiene dos vertientes: la teórica y la práctica ${ }^{35}$. De modo que ambas facetas racionales deben ser activadas por un conocer activo que, según el de Aquino, sea habitual.

Tomás de Aquino propone que la vertiente teórica de la razón es activada por el hábito de los primeros principios especulativos. En cambio, su propuesta acerca de la fase práctica de la razón dice que ésta es activada por la sindéresis: «así pues como la razón en las cosas especulativas se deduce de algunos principios por sí evidentes, acerca de los cuales versa el llamado hábito del intelecto, así también conviene que la razón práctica se deduzca de otros principios evidentes por si» 36 .

Es obvio que tenemos una facultad a la que llamamos razón. Pero una cosa es el operar propio de esa facultad, y otro el conocimiento de ella como facultad. Saber que tenemos tal potencia no es conocimiento racional ninguno. No es un conocer discursivo, argumentativo, demostrativo o conclusivo, sino otro superior; un conocer claro, intuitivo. Pero la precedente proposición tomista de que activamos con instancias cognoscitivas distintas las dos vías racionales diversas no es del todo clara, porque si la razón es una única potencia, debe ser conocida y activada por una única instancia cognoscitiva. De lo contrario se procedería a la equivocidad, pues no habría manera de comprobar cual de las dos activaciones es superior. Es mejor considerar que ambas facetas de la razón son activadas, aunque de modo distinto, por la sindéresis. O de otro modo, que la razón teórica es una activación superior de la razón que la práctica. Por tanto, la sindéresis activará de doble modo a la razón, siendo uno más activo que otro.

Con todo, Tomás de Aquino ciñe exclusivamente la activación de la sindéresis a la razón práctica. Dice, por ejemplo, que «el consejo es cierta inquisición, de donde conviene que proceda de otros principios (los de la sindéresis)» ${ }^{37}$, pero es claro que el consejo, es decir, la deliberación racional, el sopesar o aconsejarse, es un acto de la razón práctiça. A él siguen otros actos cognoscitivos prácticos como el juicio práctico, es decir, el destacar una opción por en-

32 Ibidem:

33 In II Sententiarum, d. 2, q. 2, a. 2, ad 2.

34 Summa Theologiae, I-II ps., q. 100, a. 1, co.

35 Cfr. mi libro Razón teórica y razón práctica según Tomás de Aquino, Cuadernos de Anuario Filosófico,

Serie Universitaria, $\mathrm{n}^{\circ}$ 101, Pamplona, Servicio de Publicaciones de la Universidad de Navarra, 2000.

36 In II Sententiarum, d. 24, q. 2, a. 3, co.

37 Summa Theologiae, I-II ps., q. 91, a. 4, ad 2. 
cima de las demás, y el imperio, esto es, el mandato o precepto para obrar. Y todos ellos están regidos por la sindéresis ${ }^{38}$.

El acto decisivo de la razón práctica, en vistas del cual se ejercen los precedentes, es el imperio. Si imperamos bien lo que debemos hacer, esto es, si mandamos con rectitud racional, adquirimos por medio de la repetición de estos actos el hábito culminar de la razón práctica, la prudencia ${ }^{39}$, en vistas del cual se adquieren los precedentes hábitos de la razón práctica (la eubulia, y la synesis-gnome). Pero en el corpus tomista es manifiesto que «la sindéresis mueve a la prudencia» ${ }^{40}$.

\section{LA SINDÉRESIS ACTIVA E ILUMINA LA VOLUNTAD}

Terminamos de ver cómo, según Tomás de Aquino, la sindéresis dirige la razón práctica. Pero es sabido que la razón práctica versa sobre lo operable, sobre las acciones que caen bajo el poder factible humano, y es claro que éstas no se ejercen sin el querer de la voluntad. Por eso se afirma que «la prudencia no está sólo en la razón, sino que tiene algo en el apetito» ${ }^{41}$. Esbocemos ahora, por tanto, la vinculación entre la sindéresis y la voluntad.

En una tesis tomista se declara que «así como nada consta firmemente según la razón especulativa sino por resolución a los primeros principios indemostrables, así nada consta firmemente por la razón práctica sino por la ordenación al último fin, que es el bien común» ${ }^{42}$. Pero cuando se habla de fin y de bien, se habla de la voluntad, pues aquéllos son su objeto real propio. De modo que si la razón práctica está abierta al fin y al bien, ésta será la ayuda que la razón presta a la voluntad para que ésta última se adapte a su propio objeto. Pues bien, se puede sostener que voluntad es activada en orden a la consecución del fin último felicitario por una instancia superior a ella, la sindéresis, y es ayudada por la razón práctica en orden a adaptarse a los medios que permiten la consecución de dicho fin.

No obstante, si la sindéresis es la mirada abierta nativamente que descubre el sentido, la verdad, de la voluntad en su estado natural, es decir, su naturaleza como intención de alteridad, de fin último, también acompañará a la voluntad en todo su recorrido, que, como intención de bienes mediales, irá descubriendo el sentido de la voluntad como inclinación al bien último a través de tales bienes. Ahora bien, en ese adaptarse al fin la voluntad crece, se activa como potencia en atención al fin último, y este crecimiento no es otra cosa que la virtud ${ }^{43}$. Pero es claro que para Tomás de Aquino «la razón natural establece el fin en las (virtudes) morales, la cual se llama sindéresis... El fin no pertenece a las virtudes morales en cuanto que éstas establezcan el fin, sino porque tienden al fin establecido por la razón natural» ${ }^{44}$. De manera

38 «In prima applicatione qua applicamur scientia ad actum ut sciatur an factum sit, est applicatio ad actum particularem notitiae sensitivae, ut memoriae, per quam eius quod factum est, recordamur; vel sensus, per quem hunc particularem actum quem nunc agimus, percipimus. Sed in secunda et tertia applicatione, qua consiliamur quid agendum sit, vel examinamus iam facta, applicantur ad actum habitus rationes operativi, scilicet habitus synderesis», $Q . D$. De Veritate, q. 17, a. 1, co.

39. Cfr. mi libro La virtud de la prudencia según Tomás de Aquino, Cuadernos de Anuario Filosófico, Serie Universitaria, ${ }^{\circ}$ 90, Pamplona, Servicio de Publicaciones de la Universidad de Navarra, 1999.

40 «Synderesis movet prudentiam», Summa Theologicae, II-II ps, q. 47, a. 6, ad 3.

41 In Ethicorum, l. VI, Iec. 7, n. 6; cfr asimismo: Summa Theologiae, II-II ps., q. 47, a. 16, co.

42 Summa Theologiae, I-II ps. q. 90, a. 2, ad 3. La tesis se puede formular en sentido contrario de este modo: «error circa finem in operabilibus (est) sicut error circa prima principia in speculativis», In II Sententiarum, d. 7, q. 1, a. 2 , co.

43 Cfr. mi libro Los hábitos adquiridos. Las virtudes de la inteligencia y de la voluntad según Tomás de Aquino, Cuadernos de Anuario Filosófico, $\mathrm{n}^{\circ}$ 118, Pamplona, Servicio de Publicaciones de la Universidad de Navarra, 2001 .

44 Summa Theologiae, II-II, q. 47, a. 6, co. 
que la sindéresis acompaña a la voluntad tanto en su estado de naturaleza como en su perfeccionamiento virtuoso ${ }^{45}$. La virtud por excelencia de la voluntad es la justicia. De modo que la sindéresis debe estar abierta a ella: «el hombre según la razón natural se inclina a la justicia» ${ }^{46}$.

De la razón natural declara Tomás de Aquino que es la instancia que conoce las virtudes morales, aún en el caso de la persona que carece de ellas ${ }^{47}$; y esto, hasta tal punto que establece el fin de éstas ${ }^{48}$. De modo que, si las virtudes morales tienen como sujeto a la voluntad, la razón natural debe conocer el fin de la voluntad. Pero difícilmente conocerá el fin de la voluntad sin conocer a esta potencia, pues es claro que ésta facultad no es otra cosa es una relación real al fin último; es decir, la voluntad es una relación trascendental al fin último («relación de la voluntad al fin último» ${ }^{49}$ ). Esta relación es tal que «el respecto de la relación depende del término al que pertenece la relación ${ }^{50}$. Pero el fin de la voluntad en último término es Dios. De manera que se puede hablar de la «relación de la voluntad a Dios» ${ }^{51}$. Así que, si la razón natural o sindéresis empuja a la voluntad al fin, en última instancia la empuja a adaptarse a Dios.

La voluntad, como es obvio, no está abierta sólo al bien o fin último, sino también a muchos bienes mediales. De modo que si esta potencia recibe la moción de la sindéresis, la sindéresis también deberá mover y conocer a la voluntad en la medida en que ésta se inclina a los me$\operatorname{dios}^{52}$. Además, si la voluntad mueve a obrar en lo particular, no podría hacerlo sin la moción universal de la razón natural o sindéresis ${ }^{53}$. Y a su vez, el que la voluntad mueva a obrar a otras potencias, no puede entenderse sin que la voluntad reciba para ello el impulso de la sindéresis ${ }^{54}$.

Si ahora unificamos lo dicho en los dos últimos epígrafes, tenemos que si la sindéresis arroja luz sobre la razón y sobre la voluntad, y ello tanto en el estado natural de esas potencias, como en su crecimiento por medio de hábitos y virtudes, respectivamente, entonces debemos concluir que el «objeto» propio de la sindéresis es lo psíquico. Tal «objeto» no es ningún objeto intencional, ninguna idea, ninguna forma, sino un cúmulo de realidades, aunque no físicas. La sindéresis no forma nada al conocer; no objetiva ninguna semejanza de alguna realidad extramental existente o irreal, sino que al conocer suscita actos reales en la inteligencia y voluntad inexistentes antes en ellas. Tales actos son tanto las operaciones inmanentes de inteligencia y de la voluntad como los hábitos y virtudes de ellas, cuya nota común a todos ellos es, precisamente, su carácter activo.

45 «Perfectio virtutis moralis, de qua nunc loquimur, consistit in hoc, quod appetitus regularetur secundum rationem. Prima autem rationis principia sunt naturaliter nobis indita, ita in opèrativis sicut in speculativis. Et ideo sicut per principia praecognita facit aliquis inveniendo se scientem in actu: ita agendo secundum principia rationis practicae, facit aliquis se virtuosum in actu», In Ethicorum, I. II, 1c. 4, n. 7.

46 «Homo secundum naturalem rationem ad iustitiam inclinatur, peccatum est contra naturalem rationem», Summa Theologiae, II-II ps., q, 183, a. 4, co; «naturale est quod homo refugiat proprii corporis detrimentum, vel etiam damna temporalium rerum, sed quod homo propter ista recedat a iustitia, est contra rationem naturalem», $I b i$ dem, q. 19 , a. 3 , ad 3.

47 «Amor castitatis potest delectare non solum eum qui castitatem habet, sed etiam eum qui virtute castitatis caret, in quantum per rationem naturalem homo iudicat bonum virtutis, et diligit ipsum et delectatur in eo, etiam si virtutem non habeat», Q.D. De Malo, q. 15, a. 2, ad 5.

48 «Virtutibus moralis praestituit finem ratio naturalis quae dicitur synderesis... non autem prudentia», Summa Theologiae, II-II ps., q. 47, a. 6, ad 1; «finis non pertinet ad virtutes morales tanquam ipsae praestituant finem, sed quia tendunt in finem a ratione naturali praestitutum», Ibidem, ad 3. «sicut enim inclinatio naturalis est a ratione naturali, ita inclinatio virtutis moralis a prudentia», In III Sententiarum, d. 33, q. 2, a. 3, co.

49 In II Sententiarum, d. 38, q. 1, a. 1, co.

50 Q. Quodlibet, q. 9, a. 2, 3, ad 2. «La razón de la relación es el respecto de uno a otro», Summa Theologiae, I ps., q. 28, a. 3, co. «la relación se dice del hecho de que se dice hacia otro», In I Sententiarum, d. 26, q. 2, a. 2, ad 3.

51 In II Sententiarum, d. 38, q. 1, a. 2, co.

52 «Ratio naturalis... potest dirigere in aliquem finem proximum», In II Sententiarum, d. 41, q. 1, a. 2 , ad 2.

53 «Ad confesionem veri debito modo faciendam ubi opportet et cui oportet, in generali inclinat ratio naturalis», In IV Sententiarum, d. 17, q. 3, a. 2, b, ad 1.

54 Cfr. In III Sententiarum, d. 33, q. 1, a. 2, b, ad 2. 


\section{EL PROBLEMA DE LOS PRIMEROS PRINCIPIOS PRÁCTICOS}

En este punto surge un problema de compatibilidad doctrinal. En efecto, si acabamos de mantener que el tema real propio de la sindéresis o razón natural es lo que hemos llamado lo psiquico de la naturaleza humana ¿cómo armonizar esto con esa otra tesis tomista según la cual su tema son los primeros principios prácticos? Efectivamente, «sus principios (de la razón humana) inherentes por naturaleza, son ciertas reglas y medidas de todas las cosas que deben ser realizadas por el hombre, de las cuales la razón natural es regla y medida ${ }^{55}$. Además, parece que los primeros principios son plurales ${ }^{56}$. ¿De qué principios se trata?

Seguramente la clave para la solución del precedente interrogante pase por tener en cuenta que «el bien es lo primero que cae bajo la razón práctica; por eso, el bien es lo que todas las cosas apetecen es el primer principio práctico ${ }^{57}$. Pero ¿de que bien se trata? A mi modo de ver, no puede ser otro que el actuar bien, y ello para todas las facultades y funciones humanas. Con ello se explica por qué se habla en plural de los primeros principios prácticos, pues cada facultad tiene su modo propio de actuar correctamente. De modo que a lo que impele la sindéresis a cada potencia es a que su operatividad propia sea recta. Es decir, la activación de la sindéresis a cada potencia es algo así como un «¡actúa bien!», o sea, «actúa según tu modo de ser», «según tu diseño originario y el fin que debes perseguir». Pero como cada potencia es distinta, su activación debe ser distinta, a pesar de que a todas active e impulse a actuar bien.

Por lo demás, se nos declara que los primeros principios son obvios ${ }^{58}$, que, por tanto, «en los primeros principios conocidos naturalmente tanto sean especulativos como prácticos, nadie puede errar ${ }^{59}$. Esto lo podemos comprender en el sentido de que todos sabemos que nuestras facultades y funciones humanas están diseñadas nativamente para actuar, para no quedarse en la inactividad, y para hacerlo bien. El que los principios son «indemostrables» ${ }^{60}$, se puede interpretar en el sentido de que nadie se pregunta por qué las facultades humanas están diseñadas para la buena actuación. No se puede dudar de ellos porque «nunca se abandonan» o lo que es lo mismo, que «el hombre siempre los retiene» ${ }^{61}$. De manera que el «ihaz el bien!» es la moción de la sindéresis a toda potencia de la naturaleza humana, y no sólo a la voluntad. Y lo es porque sólo en su mano está saber cuál es el modo de ser de las potencias humanas, es decir, lo psíquico.

55 Summa Theologiae I-II ps., q. 91, a. 3, ad 2.

56 «Prima principia indemostrabilia sunt plura. Ergo etiam praecepta legis naturae sunt plura», Summa Theologiae, I-II ps., q 94, a. 2, sc.

57 Summa Theologiae, I-II ps., q 94, a. 2, co. «In ratione practica praexistunt quaedam ut principia naturaliter nota, et huiusmodi sunt fines virtutum moralium, quia finis se habet in operabilibus sicut principium in speculativis», Ibidem, II-II ps., q. 47, a. 6, co.

58 «liarum scientiarum principia vel sunt per se nota, et probari non possunt, vel per aliquam rationem naturalem probantur in aliqua alia scientia», Summa Theologiae, I ps, q. 1, a. 6, ad 2; «prima praecepta communia legis naturae sunt per se nota habenti rationem naturalem, et promulgatione non indigent», Ibidem, q. 100, a. 4, ad 1 .

59 «In primis enim principiis naturaliter cognitis, sive sint speculativa sive sint operativa, nullus potest errare», Quodlibet, 3,12, 1, co. Otros lugares paralelos son: «in nobis sunt quaedam potentiae et habitus cognoscitivi in quibus nunquam falsitas esse potest, sicut sensus, et scientia, et intellectus principiorum», Q.D. De Veritate, q. 2, a. 12, co; «quaedam sunt vera in quibus omnes homines concordant, sicut sunt prima principia intellectus tam speculativis quam practici», Summa Contra Gentes, 1. III, cap. 47, n. 6; «circa prima principia, ex quibus etiam accidit infabilitus veritatis», Summa Theologiae, I ps., q. 85, a. 6, co; «sic igitur patet quod, quantum ad communia principia rationis sive speculativae sive practicae, est eadem veritas seu rectitudo aput omnes, et aequaliter nota», Ibidem, I-II ps., q. 94 , a. 4 co.

60 Cfr. Summa Theologiae, II-II ps., q. 91, a. 3, co.

61 In II Sententiarum, d. 24, q. 2, a. 3, ad 5. En otros textos anota: «Huiusmodi autem sunt habitus primorum principiorum, tam speculabilium quam practicorum, qui nulla oblivione vel deceptione corrumpi possunt», Summa Theologiae, I-II ps., q. 53, a. 1, co. «Habitus qui est in ratione potest oblivioni tradi, sicut ars et scientia, nisi sit habitus naturalis, sicut intellectus», In Ethichorum, 1. VI, 6, Ic. 4, n. 14. 


\section{LA SINDÉRESIS Y LOS HÁBITOS INNATOS}

Los hábitos innatos, según Tomás de Aquino, son tres: la sindéresis, el de los primeros principios especulativos, al que también llama intellectus, y la sabiduría. La sindéresis es el inferior de todos ellos. Por eso se puede considerar que es el puente o vínculo de unión de la persona humana con su naturaleza. Por su parte, el tema de los primeros principios especulativos son los primeros principios reales. No puede ser el tema del intellectus la naturaleza humana, porque, obviamente, ésta no es ningún primer principio, sino que ha sido concreada con la persona humana en segundo lugar, pues es claro que ha venido a este mundo estando los primeros principios bien asentados; y ha venido, no para quedarse al margen de ellos, sino para tener que ver con ellos. Por otro lado, el tema del hábito de sabiduría, es, sobre todo, el propio cognoscente humano, es decir, la misma persona humana como ser cognoscente abierto a la totalidad de lo real, y en especial a su Creador; y ello, en la medida en que un hábito innato solidario de la persona alcanza a ésta.

Pero si uno se pregunta cuál es la relación entre la sindéresis y los demás hábitos innatos, uno parece enfrentarse al misterio, tanto en el corpus tomista como en el resto de la filosofía, pues apenas hay indicaciones sobre ello. Ya hemos visto como Tomás de Aquino establece la comparación de que así como la razón práctica se refiere a la sindéresis, así la especulativa al intelecto ${ }^{62}$. Pero ¿qué relación guarda la sindéresis con el intelecto de los primeros principios? Una sucinta respuesta dice así: «en el alma existe algo que tiene perpetua rectitud, a saber, la sindéresis, la cual, sin duda, no pertenece a la razón superior, sino que se refiere a la razón superior como el intelecto de los principios al razonamiento de las conclusiones» ${ }^{63}$. Por lo menos se nos descubre que la sindéresis no es lo superior en el conocimientos humano. Se llama tradicionalmente razón superior desde San Agustín a esos conocimientos humanos cuyo tema son las realidades supremas. Por eso, tanto el intellectus como la sabiduría se encuadran dentro de la ratio superior, porque sus temas son, respectivamente, los primeros principios reales y la vinculación de la persona humana, como persona, con ellos. En cambio, como la sindéresis mira hacia lo inferior, hacia lo más bajo que ella, la naturaleza humana, se encuadra dentro de la ratio inferior.

Con todo, algo más podemos deducir de esta relación que se busca. En efecto, si tratamos de la sindéresis, es porque algún conocimiento de ella tenemos, y no sólo de su existencia, sino también de su índole. Pero como ningún conocimiento es autointencional, la sindéresis debe ser conocida desde otra instancia cognoscitiva superior. Ahora bien, superior cognoscitivamente a la sindéresis son el intellectus o hábito de los primeros principios teóricos, el hábito de sabiduría y el intelecto agente. Ya hemos aludido a que el tema del hábito de los primeros principios son los primeros principios reales, y la sindéresis no es ningún principio real. De modo que no parece que la sindéresis pueda ser tema del intelellectus.

Por otra parte, al conocer la sindéresis, notamos que aquello que nos permite conocerla es un conocer que nosotros tenemos, no un conocer que somos. De manera que tal instancia cognoscitiva debe ser una posesión, un hábito. Y es claro, que superior al intellectus, tenemos el hábito de sabiduría. Por tanto, aunque sólo sea por exclusión, habrá que concluir que, aunque la sindéresis no sea el tema primero del hábito de sabiduría, al menos debe caer en su órbita. De manera que la relación que guarda el hábito de sabiduría con la sindéresis es que la primera es cognoscitiva de la segunda. Y la relación que guarda el intellectus con la sindéresis no es directa, sino a través de sus temas, pues los primeros principios reales, tema del intellectus, son

62 «icut enim ratio in speculativis deducitur ab aliquibus principiis per se notis, quorum habitus intellectus dicitur; ita etiam oportet quod ratio practica ab aliquibus principiis per se notis deducatur», In II Sententiarum, d. 24, q. 2, a. 3, co. Cfr. también: de ese artículo el ad 1.

63 In II Sententiarum, d. 24, q. 3, a. 3, ad 5. 
el fundamento y fin, la garantía por tanto, del desarrollo de la actuación humana, tema que ilumina la sindéresis.

No parece oportuno decir, en fin, que la sindéresis sea tema del intelecto agente porque, en sentido fuerte, «el intelecto agente (es) uno con el hombre según el ser substancial» ${ }^{64}$, de modo que no es ni un hábito ni una potencia, sino que forma parte del acto de ser personal humano. Por tanto, no es un conocer que se tiene sino que se es.

\section{SINDÉRESIS, INTELECTO AGENTE Y DIOS}

Tomás de Aquino indica que todos los hábitos innatos se deben a la luz del intelecto agente: «si algún hábito existe en el intelecto posible inmediatamente causado por el intelecto agente, tal hábito es incorruptible por sí y por accidente. De este estilo son los hábitos de los primeros principios, tanto especulativos como prácticos» ${ }^{65}$, es decir, también la sindéresis. Por lo demás, ya se ha anunciado que el sujeto de tales hábitos no puede ser el entendimiento posible, y que no queda más posibilidad que sea el intelecto agente.

Pero si los hábitos innatos dependen directamente del intelecto agente ello indica, por una parte, que son menos activos que él, y, por otra, que deben estar a su servicio, es decir, que son como sus instrumentos: «en nosotros existen como instrumentos del intelecto agente, por cuya luz está vigente en nosotros la razón natural» ${ }^{66}$. De modo que la sindéresis o razón natural es el instrumento del intelecto agente para atravesar de sentido, de verdad, a la naturaleza humana. Así como por el hábito de sabiduría sabemos qué es ser persona, por la sindéresis vemos qué es ser hombre.

Si preguntamos, pues a quién se debe la luz natural de la sindéresis, luz que tenemos para conocer todo lo que nos pasa en nuestra naturaleza, la respuesta es que tal luz depende, o es instrumento, del intelecto en acto o agente. De modo que la sindéresis requiere de un origen más recóndito en nosotros. Por ello, la sindéresis es un conocer derivado e inferior al intelecto agente y no puede arrojar luz sobre éste. Por lo demás, el intelecto agente conforma, a mi modo de ver, lo que se puede denominar intimidad o corazón humano. En consecuencia, debido a la inferioridad cognoscitiva de la sindéresis sobre el intelecto como acto, ésta no alcanza a conocer al intelecto agente: «las realidades escondidas en el corazón son de aquellas cosas a las que no se puede extender la razón natural» ${ }^{67}$. Por lo demás, el intelecto agente es «impreso en nosotros inmediatamente por Dios» ${ }^{68}$.

Por otra parte, si, como se ha visto, la sindéresis dirige a la voluntad en su inclinación al fin último, y éste es Dios, en consecuencia, de alguna manera la sindéresis estará abierta a Dios: «ciertas cosas existen a las que la razón natural puede alcanzar, como que Dios existe, que Dios es uno, y otras de este estilo» ${ }^{69}$. En este pasaje, como en los que se añaden más abajo, «razón natural» se toma en sentido amplio, esto es, como significando que el conocer humano, sin pre-

64 Summa Contra Gentiles, 1. III, cap. 42 , n. 7.

65 Summa Theologiae, I-II ps., q. 53, a. 1, co. La sindéresis «est quodammodo innatus menti nostrae ex ipso lumine intellectus agentis, sicut et habitus principiorum speculativorum», In II Sententiarum, d. 24, q. 2, a. 3, co.

66 Q.D. De Veritate, q. 10, a. 13, co. Esta tesis TOMÁs DE AQuino la tomó de AvERroes, el cual la expone en su Comentario al libro III De Anima.

67 Q.D. De Veritate, q. 18, a.4, ad 14.

68 Q.D. De Spiritualibus Creaturis, q. un., a. 10, co. Las razones que corroboran esto se encuentran también en: $Q . D$. De Anima, q. un., a. 5, co y ad 6 y 9; Summa Theologiae, I ps., q. 79, a. 4, co y ad 5.

69 Summa Contra Gentes, 1. I, cap. 13, n. 2. Y en otra parte: «perceptio divinae veritatis quae fit per rationem naturalem, tendit, sicut in id cui innititur, in intellectum principiorum», In III Sententiarum, d. 25, q. 1, a. 1, a, ad 4; «per rationem igitur naturalem cognosci possunt de Deo ea quae pertinent ad unitatem essentiae, non autem ea quae pertinent ad distinctione personarum», Summa Thelogiae, I ps., q. 32, a. 1, co. Cfr. también: Ibidem, I-II ps., q. 103 , a. 3 , co. 
cisar qué nivel, está naturalménte abierto a Dios, sin necesidad de ayuda sobrenatural. Con todo, esa expresión se puede tomar también muchas veces como equivalente a sindéresis.

Con todo, esa apertura a Dios es meramente natural. No se trata, por tanto, de la apertura al fin sobrenatural. Pero como todo hombre dispone de razón natural ${ }^{70}$, todo hombre está abierto por ella a Dios ${ }^{71}$. Y además de estar abierto por la luz cognoscitiva natural a Dios, también lo está a otras cosas «de este estilo» a las que alude Tomás de Aquino, que no son otra cosa que lo que ratifican los preceptos del decálogo ${ }^{72}$, pues todos ellos no son sino explicitación de lo que es el recto ejercicio de las facultades humanas, que deben ser gobernadas por la sindéresis. De modo que, si no se ejercen esas potencias según el modo de ser natural de éstas, es la sindéresis la que denuncia su mal ejercicio. Asimismo, dado que la razón natural está abierta a Dios y es de ella de quién depende dirigir y gobernar todas las potencias humanas, en su dictamen estará que éstas rindan de algún modo culto a $\operatorname{Dios}^{73}$.

Por último, para Tomás de Aquino a la razón natural o sindéresis pertenece lo que él llama la ley natural $^{74}$. Por eso es comprensible que exponga que «los preceptos morales siguen a la naturaleza humana, ya que son propios del dictamen de la razón natural. Y por eso permanecen los mismos en cualquier ley, y en cualquier estado del hombre» ${ }^{75}$. Con todo, éstos se pueden ver no con total claridad, puesto que la luz natural de la sindéresis en cierta medida ya está oscurecida $^{76}$ y en cierta medida se puede oscurecer todavía más, aunque no completamente ${ }^{77}$.

70 «Praesciti et infideles, et etiam antichristus, non privantur interiori auxilio naturalis rationis», Summa Theologiae, I ps., q. 113, a. 4, ad 3.

71 «Cognitio Dei per essentiam, cum sit per gratiam, non competit nisi bonis, sed cognitio eius quae est per rationem naturalem, potest competere bonis et malis», Summa Theologiae, I ps., q. 12, a. 12, ad 3.

72 He aquí unos pasajes paralelos: «praecepta decalogi praecipiunt et prohibent ea quae manifeste ratio naturalis habet ut fiant vel non fiant: cadunt enim in conceptione communi», Q.D. De Malo, q. 14, a. 2, rc. «Praecepta decalogi sun inmediate a Deo populo tradita; unde secundum hanc formam traduntur prout sunt manifesta naturali rationis cuiuslibet hominis etiam popularis. Quilibet autem statim ratione naturali advertere potest adulterium esse peccatum», Ibidem, q. 15, a. 2, ad 3. «Praecepta decalogi, sicut data sunt omni populo, ita etiam cadunt in aestimatione omnium, quasi ad naturalem rationem pertinentia. Praecipue autem sunt de dictamine rationis naturalis fines humanae vitae, qui se habent in agendis sicut principia naturaliter cognita in speculativis», Summa Theologiae, IIII ps., q. 56, a. 1, co. «Praecepta decalogi sunt prima praecepta legis, et quibus statim ratio naturalis assentit sicut manifestissimus... Et ideo praecepta decalogui oportuit ad iustitiam pertinere», Ibidem, q. 122, a. 1, co. Tanto los preceptos formulados de modo positivo como en negativo: «regula autem actionis, quia constituit medium inter superfluum et diminutum, necesse est ut quaedam resecet et quaedam statuat. Unde et in ratione naturali debent, quaedam praecepta negativa, quaedam affirmativa continentur», Q.D. De Malo, q. 2, a.1, co.

73 «De dictamine rationis naturalis est quod homo aliqua faciat ad reverentiam divinam, sed quod haec determinate faciat vel illa, istud non est de dictamine rationis naturalis, sed de institutione iuris divini vel humani», Summa Theologiae, II-II ps., q. 81, a. 2, ad 3.

74 «Ratio naturalis... quae dicuntur ad legem naturae pertinere... Per contrariam consuetudinem, qua multi in peccato praecipitabantur, iam apud multos ratio naturalis, in qua scripta erant, obtenebrata erat..., In III Sententiarum, d. 37 , q. 1, a. 1, co.

75 «Praecepta moralia consecuuntur naturam humanam, cum sit de dictamine rationis naturalis; et ideo permanent eadem in qualibet lege, et in quolibet statu hominis», In IV Sententiarum, d. 2, q. 1, a. 4, a, ad 2.

76 Antes del pecado original «Adam autem non solum sciebat illa de Deo quae naturali ratione cognosci possunt, sed etiam amplius, nec tamen ad videndum Dei essentiam pervenerat», Q.D. De Veritate, q. 18, a. 3, co; «ita quidquid seminaliter sive virtualiter erat in primis principiis rationis, totum erat explicitum secundum perfectam cognitionem eorum omnium ad quae virtus primorum principiorum se extendere poterat. Unde dicendum est, quod quidquid unquam homo aliquis de cognitione rerum naturali ingenio assequi potuit, hoc totum Adam naturali cognitione habitualiter scivit», Ibidem, q. 18, a. 4, co. Pero la historia posterior fue muy distinta: «immediate post peccatum primi parentis, propter doctrinam ipsius Adae, qui plene instructus fuerat de divinis, adhuc fides et ratio naturalis vigebat in homine in tantum quod non oportebat determinare hominibus aliqua signa fidei et salutis... Sed circa tempus Abrae... obscurata etiam ratio naturalis per augmentum carnalis concupiscentiae usque ad peccata contra naturam», Summa Theologiae, III ps., q. 70, a. 2, ad 1.

77 «er infidelitatem non corrumpitur totaliter infidelibus ratio naturalis, quin remaneat in eis aliqua veri cognitio», Summa Theologiae, II-II ps., q. 10, a. 4, ad 3. «Lumen naturalis rationis. Hoc autem lumen, cum pertineat ad speciem animae rationalis, nunquam privatur ab anima. Impeditur tamen quandoque a proprio actu per impedimenta virium inferiorum, quibus indiget intellectus humanus ad intelligendum», Summa Theologiae II-II ps., q. 15, a. 1, co. 
Obviamente lo que precede conecta directamente con la ética. En efecto, si se usan las facultades de la naturaleza humana según ellas son: comportamiento ético. Si se usa de ellas sin tener en cuenta su modo de ser y su fin: comportamiento no ético. Pero quien declara si se usa según o de las facultades humanas es la sindéresis. De modo que también es explicable que una época de relativismo ético, como la nuestra, sea compatible con el desconocimiento de la sindéresis.

Se comenzó indicando que la psicología no parece alcanzar el estatuto de ciencia porque se desconoce su tema propio, lo psíquico en su estado de naturaleza, y que, correlativamente, se desconoce el método apropiado para alumbrar ese tema: la sindéresis. Ahora se puede terminar indicando que se recela del carácter de ciencia de la ética, porque se desconoce su tema, el desarrollo de lo psíquico (nociones de hábito y virtud), a la par que se desconoce la instancia que activa y conoce tal desarrollo: la sindéresis.

Juan Fernando Sellés Departamento de Filosofía

Universidad de Navarra 31080 Pamplona

e.mail: jfselles@unav.es 